\title{
NOVOS IDOSOS, NOVOS DIREITOS: uma reflexão contemporânea
}

\section{NEW ELDERLY, NEW RIGHTS: a contemporary reflection}

\author{
Gizella Maia Ribeiro Bolognese ${ }^{1 *}$ \\ ${ }^{1}$ Advogada, Mestranda em Direito pela Faculdade Autônoma de Direito. \\ *Autora correspondente: E-mail: bolognese70@hotmail.com
}

DOI: https://doi.org/10.53817/1983-6929-ragg-v12n1-7

\section{RESUMO:}

Introdução: países em desenvolvimento, como é o caso do Brasil assistem perplexos a um rápido envelhecimento da população e suas consequências, incluido as do âmbito da preservação dos direitos fundamentais. Em 1994 foi promulgada a Política Nacional do Idoso, assegurando direitos sociais a pessoa idosa, através da promoção da sua autonomia, integração e participação. Ao longo dos 27 anos que separam a promulgação desta política até os dias de hoje, existe uma trajetória social e jurídica que deve ser avaliada sob a ótica da contemporaneidade. Objetivo: analisar principais aspectos históricos relacionados aos novos direitos dos idosos, considerando os principais marcos jurídicos a eles relacionados. Métodos: foi conduzida uma revisão narrativa com base em documentos jurídicos e literatura publicada sob a forma de periódicos e livros indexados no Scielo, Google Acadêmico e Banco de Teses da CAPES. Resultados: Diante do cenário das lutas sociais e da influência de eventos internacionais, foram destacadas neste texto, a Política Nacional do Idoso, o Estatuto do Idoso e a Política Nacional de Saúde do Idoso, com especial ênfase no Estatuto do Idoso o qual unificou leis e normas relativas aos idosos que se encontravam dispersas. Sobre este tema, esta revisão narrativa compila e analisa algumas estatísticas sobre o futuro do envelhecimento no Brasil e apela para uma reflexão da sociedade no que tange à eficácia das políticas públicas garantidoras dos direitos da pessoa idosa. A revisão também apresenta subsídios para a compreensão da importância de assegurar a todos os cidadãos idosos, os direitos que lhes são reconhecidos na legislação refletindo sobre o arcabouço legal específico e sua respectiva efetivação na vida das pessoas idosas.

Palavras-chave: Idoso, Novos Direitos, Envelhecimento, Políticas Públicas, Qualidade de Vida 


\begin{abstract}
:
Introduction: developing countries, such as Brazil, are perplexed to witness a rapid population aging and its consequences, including those within the scope of the preservation of fundamental rights. In 1994, the National Policy for the Elderly was enacted, ensuring social rights for the elderly, through the promotion of their autonomy, integration and participation. Over the 27 years that separate the enactment of this policy until today, there is a social and legal trajectory that must be evaluated from the perspective of contemporaneity. Objective: to analyze the main historical aspects related to the new rights of the elderly, considering the main legal frameworks related to them. Methods: a narrative review was conducted based on legal documents and literature published in the form of journals and books indexed in Scielo, Academic Google and CAPES Theses Bank. Results: Given the scenario of social struggles and the influence of international events, the National Elderly Policy, the Elderly Statute and the Elderly Health National Policy were highlighted in this text, with special emphasis on the Elderly Statute, which unified laws and norms related to the elderly who were dispersed. On this topic, this narrative review compiles and analyzes some statistics on the future of aging in Brazil and calls for a reflection by society regarding the effectiveness of public policies guaranteeing the rights of the elderly. The review also provides subsidies for understanding the importance of assuring all elderly citizens the rights that are recognized in the legislation, reflecting on the specific legal framework and its respective implementation in the lives of elderly people.

Keywords: Elderly, New Rights, Aging, Public Policies, Quality of Life
\end{abstract}

\title{
1. Introdução
}

Uma das características mais marcantes da atual dinâmica demográfica mundial é o processo de envelhecimento populacional, isto é, o aumento do número absoluto e do percentual de idosos no conjunto de uma dada população. Sobre este processo a Organização das Nações Unidas (ONU) divulgou em 2019 novas projeções de envelhecimento populacional para todos os países e para o mundo. Os números são impressionantes, considerando que, no mundo, em 1950 existiam 202 milhões de idosos e em 2020 1,1 bilhão. Entretanto, ao contrário de países desenvolvidos, como a Inglaterra o Brasil é um dos países de maior crescimento populacional do mundo. Enquanto, que a Inglaterra levou mais de 100 anos para aumentar a proporção de idosos da sua população, o Brasil está vivendo este processo de transição demográfica de um modo bastante rápido. Análises demográficas mostraram que a população brasileira cresceu 62 vezes entre 1800 e 2021, sendo que este maior crescimento ocorreu ao longo do século XX. Esta velocidade acelerada do envelhecimento populacional impõe desafios, não somente na área da saúde e da assistência social, mas também nas ciências jurídicas, principalmente em questões relacionadas aos direitos humanos. (VERAS e OLIVEIRA, 2018). 
O aumento na proporção de idosos não impacta somente questões como o a saúde e a seguridade social, mas também a questão dos direitos humanos relacionados a pessoa idosa. Por este motivo, em 1994 o Brasil promulgou a Política Nacional do Idoso, que foi regulamentada em 1996, considerando como pessoa idosa indivíduos com 60 ou mais anos. O cenário da promulgação desta política está imerso em um contexto histórico que transcende o País e que influenciou, posteriormente uma trajetória de lutas e ganhos políticos relacionados aos direitos dos idosos que são aqui revisados e discutidos.

\section{Métodos}

Uma revisão narrativa foi conduzida baseada em textos jurídicos publicados pelo Governo do Brasil, periódicos científicos, livros e trabalhos de conclusão em nível de mestrado e doutorado indexados no Scielo, Google Acadêmico ou Banco de Teses da CAPES. A revisão é apresentada sob a forma de tópicos temáticos mesclando informações históricas, legais e análise crítica. A revisão foi estruturada a partir dos seguintes tópicos: inicialmente será feita uma breve contextualização histórica abordando questões relacionadas com a construção desse "novo" direito que é sempre novo a cada época, porque em cada momento da história do homem, as condições materiais de existência se alteram e novas demandas se apresentam.

A seguir será destacado o que é pedagogicamente denominado "direitos de quarta geração" destacando o impacto da ciência e da tecnologia, na proteção dos velhos e novos direitos. Neste tópico, pretendo discutir questões relacionadas com o idoso se constituir em "um novo homem que envelheceu dentro de uma sociedade que o desconhece e/ou ignora, uma vez que o mesmo já não pertence ao grupo reconhecido pela sua capacidade de produção e pelo mercado de consumo. Neste tópico pretendo destacar algumas estatísticas sobre a população de idosos no futuro e as urgências de medidas que possam minimizar os impactos que virão.

A seguir, teço considerações sobre a legitimação e efetivação dos direitos dos idosos contemplando as políticas públicas brasileiras conquistadas pelos movimentos sociais e por influência de eventos internacionais, que se consolida com a criação do Estatuto dos Idosos. Este é um documento que se reveste de especial importância por reforçar os direitos fundamentais deste grupo etário da população. A Política Nacional da Saúde dos Idosos que foi instituída pela Portaria n. 2.528, também merece especial atenção e é aqui comentada, uma vez que visa à preservação da autonomia e da independência funcional da população idosa. Afinal, um dos direitos da cidadania é envelhecer com saúde! Por fim, no último tópico desta revisão, é realizada uma reflexão sobre os desafios que o futuro representa para esse grupo social. 


\section{Uma breve contextualização histórica em direção aos novos direitos dos idosos}

Após a segunda Guerra Mundial, surgiram, em razão das demandas da sociedade em evolução, os direitos supraindividuais, também chamados de direitos de terceira geração. Como bem ressalta Dotti (1980) após a Segunda Guerra Mundial, estabeleceu-se uma verdadeira 'revolução' corporificada por novas conquistas como a energia nuclear, a eletrônica e a cibernética as quais sobrepujaram os alicerces convencionais da sociedade que fixavam os limites do perigo, segurança, guerra e paz. É por este motivo que as temáticas paz, ambiente, desenvolvimento, solidariedade e fraternidade são direitos que ganharam força principalmente depois da Declaração Universal dos Direitos Humanos em 1948, documento que reúne uma síntese dos conceitos liberais do ocidente bem como da concepção socialista, e que consagra os direitos civis, políticos, econômicos e sociais dos cidadãos do mundo. A partir de então as sociedades, ao se reerguerem do caos mundial imposto pela segunda guerra, reformularam seus anseios, pois afinal, a imutabilidade não é própria do homem nem tampouco da sociedade.

O rol dos direitos fundamentais também foi reconstruído e a ele se adicionaram demandas individuais e sociais à medida que o homem seguiu buscando a felicidade. Nesse constante processo evolutivo, fronteiras geográficas, culturais e de tempo foram ultrapassadas, permitindo que, por meio da globalização, novos direitos fossem introduzidos, os direitos de quarta geração, embalados pela tecnologia e pelos avanços da biologia molecular e da manipulação genética (SANTOS, 2018). Uma vez que os direitos fundamentais se acumularam, para facilitar a sua interpretação, Karel Vasak, apresentou pela primeira vez a teoria das gerações do direito. A proposta atribuída a este doutrinador jurídico foi pela primeira vez apresentada em uma conferência ministrada em 1979 no Instituto Internacional de Direitos Humanos, em Estrasburgo, Alemanha. Esta teoria foi fortemente inspirada no lema da Revolução Francesa: liberdade, igualdade e fraternidade (Ramos, 2019). Nesta teoria, foram considerados direitos de primeira geração aqueles que garantem a liberdade individual, civil e política, os direitos de segunda geração, aqueles voltados a uma igualdade mínima econômica, social e cultural e os direitos de terceira geração, que trata sobre questões de solidariedade e fraternidade. Em sintese, a primeira geração do direito é a liberdade, a segunda é a igualdade e a terceira é a fraternidade. A partir do contexto geracional dos direitos, proposto por Vasak, outros doutrinadores jurídicos começaram a inovar, propondo novas categorias geracionais. Assim, como resultado da globalização, foi criada a quarta geração do direito associada ao pluralismo, bioética, participação democrática e limites da manipulação genética. Em síntese, 
a quarta geração preconiza a dignidade da pessoa humana contra intervenções abusivas, seja de pessoas, entidades ou mesmo do próprio Estado (Ramos, 2019).

Embora se reafirme o seu caráter puramente pedagógico, os direitos ditos de terceira e quarta geração constituem uma categoria nova chamada "novos direitos", suscitados pela evolução histórica da sociedade e, consequentemente, pela exigência de novas garantias (PEDRUZZI et al., 2017). Isso porque no caminhar da sociedade, esta sofreu alterações irreversíveis em todas as esferas das atividades humanas, criando-se novas relações e dando uma nova fisionomia à realidade social. Definitivamente, essa realidade não poderá mais ser compreendida sem a sua estrutura tecnológica, pois não existe tecnologia "fora" da sociedade, e, igualmente, não é possível, ao direito, ignorar toda essa modernização

Considerando esse novo contexto, aqui são discutidos desafios que se apresentam na atualidade, impulsionados pelos avanços tecnológicos, principalmente na medicina que proporcionaram um crescimento significativo na expectativa de vida das populações. Em contrapartida, a elevação da longevidade aumentou também os impactos sociais decorrentes dessa nova realidade, pois o reconhecido crescimento em tempo de vida, infelizmente não refletiu um equivalente acréscimo em direitos e consequentemente em qualidade de vida.

Fala-se aqui desse novo direito, fazendo um contraponto com a nova ordem mundial capitalista, fundada no aspecto econômico, onde aqueles que não estão inseridos na cadeia de produção, são inevitavelmente excluídos. Portanto, na perspectiva da sociedade capitalista a vida humana está relacionada com produtividade e consumo, fato que, do ponto de vista da lógica do capital, situa o idoso à margem da sociedade. Mais do que uma questão ética, essa é uma questão que envolve qualidade de vida, segurança, trabalho e renda, temas que precisam de um debate amplo da sociedade e de uma mudança de ângulo no olhar em relação a essa fase do desenvolvimento humano.

\subsection{Um direito em construção}

Os direitos fundamentais tiveram sua gênese no próprio direito natural do homem, que por sua vez se originou nos ideais iluministas e jusnaturalistas². São direitos inerentes à proteção do Princípio da Dignidade da Pessoa Humana que é um princípio assegurado pelas

\footnotetext{
2 Considerando uma classificação meramente pedagógica, os direitos naturais do homem são chamados de primeira geração; os de segunda geração ou segunda dimensão, seriam os Direitos da Igualdade, no qual estão a proteção do trabalho contra o desemprego, o direito à educação contra o analfabetismo, o direito à saúde, cultura, etc. Os direitos de terceira geração foram desenvolvidos no século XX. Seriam os Direitos da Fraternidade, no qual está o direito a um meio ambiente equilibrado, uma saudável qualidade de vida, progresso, etc .(SILVA, 2009)
} 
Constituições, Tratados e Convenções e cujo reconhecimento representou uma grande conquista da sociedade. Mas a afirmação desses direitos foi um processo que aconteceu dentro do contexto social de cada época. Deveu-se, em grande parte, como afirma Wolkmer (2013), a conexões com as transformações sociais. Citando Bobbio, o autor confirma que:

"Essa multiplicação histórica dos "novos" direitos processou-se [...] por três razões: a) aumentou a "quantidade de bens considerados merecedores de tutela"; b) estendeu-se a "titularidade de alguns direitos típicos a sujeitos diversos do homem"; c) $\mathrm{O}$ homem não é mais concebido como ser genérico, abstrato, “[...] mas é visto na especificidade ou na concreticidade de suas diversas maneiras de ser em sociedade, como criança, velho, doente etc."

Com a sua positivação nas Constituições, esses direitos transformaram-se em garantias para o cidadão brasileiro. Na verdade, de acordo com os ensinamentos de Bobbio, Fachin e Fachin (2020) ressaltam que:

“ [...] a positivação dos direitos humanos (de resto, qualquer direito) gera consequências importantes para as pessoas que os titulariam. Um direito humano positivado gera o dever de ser observado não apenas pelo Estado, mas também pelo poder privado e, de um modo geral, por todas as pessoas, ao tempo em que passa a ter mais força normativa. Isto ocorre em razão da densidade normativa que adquire um direito a partir do momento em que ele passa a status de norma constitucional."

Obviamente, devido a conexão com as transformações sociais, trata-se de direitos que ainda estão em construção, modificando-se e renovando-se a cada etapa da vida das sociedades, partindo de um direito natural e se projetando no constitucionalismo por meio de lutas, avanços e retrocessos. De fato, desde a origem, os direitos do homem, tem sido historicamente construídos através de movimentos revolucionários, que tiveram lugar primeiramente na Europa Continental, local onde emergiram as raízes do Constitucionalismo. (ALCÂNTARA, 2009)

Perceber os direitos a partir da sua construção histórica, também significa entender que eles nascem e se desenvolvem, transformando-se de acordo com as "configurações e anseios de cada época, em que velhos direitos vão desaparecendo e sendo substituídos por novos direitos". É nessa perspectiva que entendemos a conquista de tão amplos direitos no contexto da Constituição Federal brasileira de 1988 (FERREIRA e TEIXEIRA, 2014).

No Brasil, nos últimos anos dos governos militares foi vivenciada uma sucessão de campanhas populares em favor de anseios que a sociedade havia represado. Entre eles, destaca- 
se o movimento pelas eleições regionais que aconteceram em 1982, a campanha pelas "Diretasjá", a primeira eleição presidencial, e a convocação da Constituinte. Com a Constituinte alguns temas foram legitimados e inseridos para a construção da Carta Magna incluindo: “ os direitos das minorias, especialmente mulheres e negros; combate à discriminação de gênero e ao racismo; proteção aos portadores de deficiências físicas; direitos de crianças, adolescentes, idosos e indigenas", entre outros. (SANTILI, 2006)

Vale mencionar nesse entrelaçamento de ideias, que o Brasil vivia ainda um momento de transição, mergulhado numa grande instabilidade democrática, e disso resultou o amplo debate estabelecido no contexto da Assembleia Nacional Constituinte. É com esse olhar que se constata uma evolução concreta da nossa Lei Maior, quanto aos direitos e garantias individuais, razão por que a nossa Carta Constitucional "é considerada um marco jurídico da passagem de um regime ditatorial para um regime democrático". (GOTTERT e ARGERICH, 2013)

De fato, a Constituição brasileira de 1988 não fugiu a necessidade de registrar e garantir os direitos fundamentais do homem "incorporando a grande maioria dos direitos reconhecidos mundialmente como essenciais para assegurar a dignidade da pessoa humana". Como se constata, a "nova" Constituição solidifica a ideia do "novo direito" que emerge das "novas" necessidades e formas de viver, abarcando, ainda que formalmente, o conceito de igualdade e estabelecendo "novos" rumos para estar em sociedade. (WOLKMER e LEITE, 2016)

Adverte-se adicionalmente, que o legislador teve a preocupação de amparar o surgimento de novos direitos que não estavam previstos expressamente no texto constitucional, inserindo no artigo $5^{\circ}$, parágrafo $2^{\circ}$, uma cláusula de abertura material, marcando o dinamismo dos direitos fundamentais: “[...] os direitos e garantias expressos nesta Constituição não excluem outros decorrentes do regime e dos princípios por ela adotados ou dos tratados internacionais em que a República Federativa do Brasil seja parte”. (SARLET, 2015)

Numa interpretação digna de referência, Rocha (2003) revela como a Constituição da República brasileira de 1988 erigiu o princípio da dignidade da pessoa humana como um princípio fundamental:

"Não basta garantir o direito à vida, senão que a vida digna; não basta garantir a liberdade, senão aquela que garante a vida livre que dignifica em igualdades sociais, políticas, econômicas as pessoas humanas. Não basta existir o direito, mas aquele que realiza a justiça pensada por um povo em certo momento e em dada situação concreta. Não há direito sem justiça pensada, acreditada por um povo; não há justiça sem dignidade de todos e de cada um dos que compõem o Estado; não há direito sem princípios concretizáveis, o que depende do acatamento das 
prescrições constitucionais dos princípios que legitimam o sistema e tornam-no possível de ser eficaz socialmente para converter-se em eficaz juridicamente. (ROCHA, 2003)"

Aqui compartilho o pensamento de Santili (2006), que proclama que os "novos" direitos que emergiram na Constituição de 1988, "romperam com os paradigmas da dogmática jurídica tradicional, contaminada pelo apego ao excessivo formalismo, pela falsa neutralidade política e científica e pela excessiva ênfase nos direitos individuais". Segundo a autora os "novos" direitos foram conquistados por meio de lutas sociopolíticas democráticas e que por isso mesmo têm "natureza emancipatória, pluralista, coletiva e indivisível". Todos esses argumentos levam a novos desafios impostos à ciência jurídica pois não se limitam às estreitas balizas do dualismo público-privado exigindo que se percebam "o seu caráter inovador e a sua enorme generosidade conceitual"'.

Direito em construção é um direito que se abre para novas realidades, que a cada época se reproduz vinculando-se às necessidades humanas e aos avanços da ciência e da tecnologia. Em outras palavras, direito em construção é um direito que se transformou e ainda se transforma devido a condições históricas relativas às demandas da sociedade no decorrer do tempo. Segundo Bobbio (1992) serão sempre direitos novos, esses direitos "históricos, ou seja, nascidos em certas circunstâncias, caracterizadas por lutas em defesa de novas liberdades contra velhos poderes", por isso são novos, estão e estarão sempre em construção.

\subsection{Os direitos fundamentais da quarta dimensão}

Há que se reconhecer que a história das sociedades é complexa e que sua evolução não obedece, como bem salienta Morin (2012), regras claras, tomando, na maioria das vezes, rumos incertos e improváveis. Além disso, é compreensível que essa evolução dos direitos fundamentais, tenha sido fomentada pelo conhecimento científico e tecnológico, cujo papel na globalização e na tomada de decisões foi muito importante para os rumos que as sociedades humanas progridem. Entretanto, como salientei anteriormente, os efeitos desse processo são imprevisíveis, pois o caminho para a modernidade, ou melhor, para a hipermodernidade, imprime profundas transformações nas relações sociais, as quais se tornam altamente dinâmicas e em muitos casos, instantâneas. Como diria Bauman (2003), uma "modernidade líquida", sem forma própria, que muda muito rapidamente suas instituições, suas referências, 
seus estilos de vida, crenças e convicções. Ou seja, em uma boa parte das vezes, tudo se dilui no tempo antes de consolidar.

O nascimento dessa modernidade instantânea e da revolução tecnológica que impactou principalmente o campo da saúde humana, envolveu a sociedade numa multiplicidade de realidades que se interconectam e tornam inevitável a necessidade de analisarmos os variados problemas que emergem da mesma. Questões jurídicas impensáveis há 50 anos atrás, passam a fazer rapidamente parte do mundo social e do Direito. Como assinala Wolkmer (2013), "são 'novos' direitos que precisam ser definidos e legislados, referentes à biotecnologia, a bioética e a regulação da engenharia genética", direitos específicos vinculados diretamente com a vida humana, "como a reprodução humana assistida (inseminação artificial), aborto, eutanásia, cirurgias intrauterinas, transplantes de órgãos, engenharia genética (clonagem), contracepção e outros”. Direitos que Bobbio apud WOLKMER (2013) denomina pedagogicamente, de direitos de quarta geração, surgidos ao final do século XX e que, devido à multiplicidade dos efeitos, impõe desafiadores encargos à ciência jurídica, que tem a tarefa de regulamentar e proteger o todo social.

Um mundo perplexo emerge, a partir dessa multiplicidade de impactos anunciando o declínio dos valores sociais e exigindo novos regramentos da vida do indivíduo e da sociedade. Na realidade, esta emergência desloca a atenção primária da "proteção legal" dos cidadãos. Agora, a preocupação não é mais, somente pela vida, mas pela qualidade de vida. Sobre isto, Alves (2002) destacou que: "A taxa de mortalidade diminui, e a longevidade se estende à medida em que avança a ciência, fazendo com que o homem tenha praticamente o poder sobre a vida, determinando o nascimento e a morte do seu semelhante". Alterou-se a constituição do ser vivo, o equilíbrio ecológico, a sobrevivência das espécies, e criou-se uma realidade virtual que conectou o mundo inteiro diminuindo as distâncias.

Esses novos tempos trouxeram a necessidade de proteger especificamente alguns direitos, como é o caso da proteção dos direitos das crianças e dos adolescentes, do jovem, dos idosos, da mulher gestante aos alimentos e do consumidor, entre outros. Como pontua Feliciani (2013), para cada uma das fases da vida existem necessidades especiais que o Código Civil em vigor, "seguramente não mais pode atender", embora, diga-se de passagem, tenha sido elaborado para proteger a pessoa humana ${ }^{3}$. Assim, atendendo a "mandamentos universais e constitucionais”, leis específicas têm sido criadas com o objetivo de proteger o direito à vida e

\footnotetext{
${ }^{3}$ O Código Civil remete-se, logo em seu art. 1o, à pessoa como ser "capaz de direitos e deveres na ordem civil”.
} 
à dignidade da pessoa humana. É dentro deste contexto maior, que a proteção dos idosos tem conquistado especial atenção dos juristas e da sociedade, sobretudo em virtude do crescimento acelerado do número de pessoas idosas no mundo inteiro, e em especial do Brasil (FELICIANI, 2013)

Por outro lado, a dificuldade está centrada na incompatibilidade cultural e do "equipamento conceitual” defasado do Direito com os avanços sociais advindos das novíssimas tecnologias e também, na velocidade com que essas tecnologias impactaram a vida humana. "É necessário, portanto, transpor o modelo jurídico individualista, formal e dogmático, adequando seus conceitos, institutos e instrumentos processuais no sentido de contemplar, garantir e materializar os 'novos' direitos. (WOLKMER, 2013).

\section{Os novos idosos e os novos direitos}

Existem algumas visões estereotipadas sobre o envelhecimento da população que a literatura costuma referir. Uma delas traz a ideia negativa de que o idoso é dependente, vulnerável e frágil e, evidentemente, tal percepção resulta na elaboração de políticas públicas que reforçam essa fragilidade. Se por um lado a ideia da dependência física coloca os idosos em pé de igualdade com as pessoas deficientes, doentes e incapacitadas, hoje essa dependência tem se ampliado, ultrapassando a perspectiva biológica, passando a vincular a situação de vulnerabilidade a um fenômeno decorrente da divisão do trabalho, isto é, à ideia de improdutividade (ALMEIDA, 2019). A este respeito, Camarano e Pasinato (2004) há 15 anos atrás já destacavam que:

"A visão do idoso como intrinsecamente improdutivo leva a se pensar que mesmo que o envelhecimento seja desejável sob a perspectiva dos indivíduos, o crescimento da população idosa pode acarretar um peso sobre a população jovem e o custo de sustentá-la vir a se constituir uma ameaça ao futuro das nações." (CAMARANO E PASINATO, 2004).

Esse pensamento deu azo à preocupação com a "crise do envelhecimento" já que aponta para imagem do idoso como "grandes consumidores de recursos públicos, principalmente, de benefícios previdenciários e serviços de saúde [...] responsáveis pelos crescentes gastos sociais que pressionam as contas públicas”. (CAMARANO e PASINATO, 2004)

Não é essa a realidade em outras regiões do mundo, o que confirma a percepção de que as diferentes culturas implicam em diferentes formas de compreender essa fase da vida. Martins 
e Santos (2001) relatam que, no Oriente, o idoso tem um lugar de respeito na sociedade, porém "ser idoso hoje" no mundo ocidental significa "uma imagem e um papel social quase insignificante" [...]. Significa também tornar-se "vulnerável à precariedade econômica". E adianta:

\begin{abstract}
“O idoso é ainda vulnerável à exclusão social, pela condição de reformado, sem relação com o trabalho e com os colegas, pela dificuldade de comunicação com as gerações mais jovens, pelo isolamento em relação à família, pela perda de autonomia física e funcional e ainda pelas dificuldades da adaptação às novas tecnologias." (SANTOS, 2001).
\end{abstract}

No entanto, apesar dessas condições e dessa imagem vulnerável, mais pessoas estão vivendo mais e se tornando idosas por mais tempo. Nesse sentido é bastante conhecido o impacto sobre a estrutura etária decorrente das melhoras das condições de saúde, da redução dos níveis de fecundidade e da mortalidade, condições com significativas consequências demográficas e socioeconômicas. A própria questão da idade cronológica é difícil de interpretar, porque as diferenças individuais e de condições de vida dificultam essa conceituação. Outras consequências podem ser relatadas no tocante ao aumento da proporção de idosos na população brasileira, uma delas analisada por Wajnman, Oliveira e Oliveira (2004), é a participação na força de trabalho de uma parte importante desse grupo social. Existe, como afirmam os autores, uma inequívoca tendência de crescimento da incorporação desse estrato da sociedade na população em idade ativa (NUNES, 2004; WAJNMAN, OLIVEIRA e OLIVEIRA, 2004)

Por outro lado, o efeito demográfico, aliado à capacidade produtiva do idoso, é fundamental para que o rendimento do trabalho dessa faixa populacional na composição de sua renda pessoal e familiar seja uma realidade relevante. Como corolário dessa análise, é racional que se repense, e com urgência, nas políticas de emprego, renda e educação da população brasileira, com foco nesse contingente populacional para que seja possível equilibrar o nível de qualificação da média da população adulta. Além disso, em virtude da inevitável tendência de crescimento do número de idosos na população economicamente ativa (PEA), verifica-se que tem sido negligenciada a necessidade de criação de novos postos de trabalho com capacidade para absorver esse contingente crescente de mão-de-obra idosa "com níveis de escolaridade inferiores ao da média populacional, de qualificação muitas vezes defasada, de difícil reciclagem, mas aproveitando-se, em contrapartida, as vantagens comparativas oferecidas pela maturidade”. (WAJNMAN, OLIVEIRA e OLIVEIRA, 2004) 
O envelhecimento populacional é um fenômeno mundial, o que é possível confirmar nos informativos da Organização Mundial de Saúde, segundo os quais, o número de pessoas com idade superior a 60 anos chegará a 2 bilhões até 2050, ou seja, um quinto da população mundial. Nos países menos desenvolvidos como o Brasil, especificamente, este fenômeno será muito maior. "Segundo o Instituto Brasileiro de Geografia e Estatística em 2030, o número de idosos ultrapassará o total de crianças entre zero e 14 anos”. (IBGE, 2018).

As projeções demográficas são indicativas de que até o final do século, cerca de três quartos da população idosa ocorrerá em países do Terceiro Mundo, tornando esse grupo etário maior nesses países. Os impactos na população brasileira serão imprevisíveis, levando-se em conta que, de acordo com as estatísticas, no Brasil, o aumento da população idosa será muito maior do que o da população como um todo (numa proporção de 15 para 5) até 2025 o que “colocará o Brasil com a sexta população de idosos do mundo em termos absolutos" (Alves, 2019).

A Constituição de 1988 incorporou avanços e mereceu ser conhecida como Constituição Cidadã, como tal não deixou de prever um conjunto de normas destinadas à população idosa. De fato, no $1^{\circ}$ artigo da Constituição ficaram registrados os fundamentos do Estado Democrático de Direito, a cidadania e a dignidade da pessoa humana. Dado que o ser humano é um ser total, a dignidade da velhice não há de começar na velhice, sendo "de capital importância que os idosos sejam vistos pela sociedade brasileira como titulares de direitos, direitos dos quais são credores desde o início de sua existência e que não prescrevem na medida em que o seu tempo de existência avança”. (WOLKMER e LEITE, 2016)

O Art. $3^{\circ}$ da Constituição também elege, como objetivos fundamentais da República Federativa, "a erradicação da pobreza e da marginalização, a redução das desigualdades sociais e regionais e a supressão de todas as formas de desigualdade, inclusive as decorrentes da idade". Em face do exposto, a interpretação dos objetivos acima mencionados, tem que passar pelo conhecimento quantitativo da realidade brasileira o que é muito bem justificado por Wolkmer e Leite (2016):

[...] não é possível combater e erradicar a pobreza sem que se tenha informação acerca do número de pessoas pobres na sociedade, do nível da pobreza dessas pessoas e das causas que as levam a essa condição; também não se pode atacar a marginalização sem que se conheçam as suas principais manifestações e os seus motivos; não se podem reduzir as desigualdades regionais sem dados sobre a realidade de cada região e o que pode ser feito para que o desnível entre estas seja reduzido; de modo semelhante não se pode combater a desigualdade, especialmente 
a decorrente da idade, sem que todo o povo tenha acesso à educação e qualificação permanentes, de forma que as pessoas, notadamente as mais velhas, não venham a se encontrar em situação desfavorável em relação às mais novas. Portanto é preciso saber quantos idosos a sociedade apresenta a cada ano e quais as suas condições de vida, as suas necessidades e as suas peculiaridades.

Sobre isso, a Fundação Getúlio Vargas divulgou em 2020, uma pesquisa buscando identificar quem são os idosos brasileiros e como vivem. Segundo essa pesquisa $10,65 \%$ da população brasileira tem 65 anos ou mais e "o aumento no número de pessoas com 65 anos ou mais na população brasileira foi de $20 \%$ na comparação com os dados de 2012, quando a proporção de idosos era de 8,8\%". (AGÊNCIA BRASIL, 2020)

Sobre os rendimentos, a mesma pesquisa divulgou que a renda dos idosos corresponde a $17,44 \%$ dos $5 \%$ dos brasileiros mais ricos e 1,67\% dos $5 \%$ mais pobres, correspondendo a:

$15,54 \%$ da classe $A B, 13,07 \%$ da classe $C, 4,71 \%$ na classe $D$, e $1,4 \%$ dos idosos são da classe E. Quanto à fonte de renda, os idosos recebem 59,64\% das aposentadorias da Previdência Social, 40,78\% dos benefícios de Prestação Continuada (BPC) e apenas 0,89\% do Bolsa Família.

Com relação à educação e considerando os resultados da mesma pesquisa (2020), os idosos representam 30\% dos analfabetos. Pois bem, a Constituição determina em seu Art. 205 que "a educação, direito de todos e dever do Estado e da família, será promovida e incentivada com a colaboração da sociedade, visando ao plano de desenvolvimento da pessoa, seu preparo para o exercício da cidadania e sua qualificação para o trabalho". No Art. 208, I, reforça que o ensino fundamental é "obrigatório e gratuito, assegurado, inclusive, sua oferta gratuita para todos os que a ele não tiveram acesso na idade própria”. (WOLKMER e LEITE, 2016)

O direito à saúde também é uma garantia constitucional, como o é, o direito ao trabalho, à moradia, ao lazer e à segurança, entre outros direitos, cujo atendimento integral é imposto à responsabilidade do Estado. Aliás, no que diz respeito à saúde é pertinente fazer uma abordagem ainda que rápida, porém contextualizada sobre a constituição da Organização Mundial da Saúde (OMS) no período pós-guerra, quando se rompeu uma tradição negativista que conceituava a saúde como a ausência de doenças. A partir daquela época, passou a prevalecer um conceito segundo o qual, saúde é o estado de completo bem-estar físico, mental e social. Saúde, repetindo Coelho (2020) tornou-se "um saber social a ser empregado em políticas governamentais para elevar a qualidade de vida da população". (COELHO, 2020) 
Uma outra questão digna de aporte neste artigo é a violência contra os idosos cuja discussão torna-se pertinente principalmente devido ao aumento da expectativa de vida do idoso no Brasil, a qual, segundo Pereira, Evangelista e Freitas (2019), situa-se na faixa de oitenta anos. Essa realidade extrapola para além do problema social e se torna um verdadeiro e intrincado desafio contemporâneo para a Segurança Pública. No entendimento dos autores, "a violência contra o idoso não é determinada por classe social e sim por uma questão cultural onde os anciãos são estigmatizados como improdutivos [...], ou seja, um peso para a família que muitas vezes depende financeiramente do idoso para sobreviver"

\section{Entre a Legitimação e a Efetivação de Direitos}

A hipermodernidade, como visto em tópico anterior, implica em reconhecer que a positivação dos direitos dos idosos, tanto na Constituição de 1988 quanto no Estatuto do Idoso, abrangeu formalmente toda uma gama de direitos, no entanto são enormes as dificuldades na efetivação dos mesmos. Para começar, sem nenhuma pretensão de abarcar todos os argumentos e conceitos que envolvem a questão dos direitos dos idosos, tem que se considerar que a humanidade é plural e que, quando se trata de idosos, não levar em conta essa pluralidade, resulta em conceitos totalmente distorcidos e desvinculados da realidade. Existe ainda uma pluralidade entre os "idosos dos idosos", pois segundo Ferreira e Teixeira (2014), trata-se de uma faixa etária com idade mais avançada dentro desse grupo da terceira idade. É natural, portanto, que esse envelhecimento populacional extremamente diversificado, determine grandes desafios para a própria ciência jurídica e para a elaboração de políticas, a fim de que os direitos positivados (postos em lei) na Constituição e legislação específica, sejam efetivamente garantidos.

Por outro lado, é extremamente positivo que, numa sociedade onde o individualismo e o imediatismo são erigidos a valores elogiáveis, a problemática do envelhecimento esteja presente cada vez mais em discussões científicas, acadêmicas ou mesmo entre particulares. Manifesta-se, dessa forma, o enfrentamento do problema afirmando que "somente ter um status de cidadão, em tese, não basta". A garantia escrita dos direitos dos cidadãos "nos instrumentos legais através da Constituição Federal, da Política Nacional do Idoso e do Estatuto do Idoso, não assegura, de imediato, uma velhice vinculada à melhoria das condições de vida. (FERREIRA e TEIXEIRA, 2014) 
Ressalta-se que o Brasil é signatário da Convenção Interamericana sobre a Proteção dos Direitos Humanos das Pessoas Idosas, cujo escopo é "a promoção e a proteção dos direitos dos idosos, com o de reconhecimento de que todas as liberdades fundamentais e os direitos humanos existentes também se aplicam a eles em sua forma plena e em igualdade de condições com os demais". (PEREIRA, EVANGELISTA e FREITAS, 2019)

Desnecessário dizer quão dispensável é a recomendação acima, mas por serem mais seletivas, as políticas públicas refletem a participação do Estado no sentido de garantir o pleno exercício da cidadania a todos os indivíduos, concebidos como cidadãos e portanto, detentores de direitos. A legitimidade com relação aos direitos dos idosos é assegurada em dispositivos legais como a Política Nacional do Idoso, o Estatuto do Idoso e a Política Nacional de Saúde do Idoso e, embora sejam grandes as dificuldades para a concretização dessas políticas, entende-se que houve um avanço quanto ao seu reconhecimento.

Essas políticas, evidentemente, refletiram conjunturas internacionais, entre as quais podem ser citadas, como impulsionadoras de novos ventos, a Assembleia Mundial sobre o Envelhecimento, na cidade de Viena, em 1982, na sua sequência, em 1999, o Ano Internacional do Idoso, uma iniciativa das Nações Unidas e a Assembleia Mundial ocorrida em Madri, em 2002. Esses eventos que resultaram de um Plano Internacional de Ações sobre Envelhecimento promovido pela Organização das Nações Unidas (ONU), chamaram a atenção para o problema do envelhecimento no mundo e encorajaram o desenvolvimento de uma política internacional voltada para o envelhecimento no século XXI. (FERREIRA e TEIXEIRA, 2014)

Falando especialmente de Brasil as recomendações das Assembleias Mundiais foram difundidas lentamente, introduzindo de forma gradual a problemática do envelhecimento nas políticas públicas a partir da atuação de alguns sujeitos como a Sociedade Brasileira de Geriatria e Gerontologia (SBGG), a Associação Nacional de Gerontologia (ANG), o SESC com seus programas pioneiros para a terceira idade, e outras ações da sociedade civil organizada. (FERREIRA e TEIXEIRA, 2014)

No entanto, é inegável que, desde a promulgação da Constituição de 1988, como já afirmado anteriormente, o reconhecimento dos direitos da população idosa, abriu as portas para um ganho social maior. De acordo com Camarano e Pasinato (2004) deu-se a incorporação da rede de proteção social ao direito de cidadania e aprovou-se a Política Nacional do Idoso (PNI) 
em 4 de janeiro de $1994^{4}$. Vale ressaltar aqui que a Política Nacional do Idoso, impactada pelas propostas neoliberais que afetaram o país, não apenas no campo econômico, mas principalmente na política social, deixa de ser prioridade do Estado o qual repassa sua responsabilidade como garantidor de direitos, para a sociedade civil ${ }^{5}$. Falando-se em efetivação de direitos, fica patente que as garantias expressas na PNI, não se traduzem em ações efetivas, uma vez que dividem as responsabilidades, descentralizando a execução e implementação da política. Isso significa que o Estado diminui sua intervenção direta e divide a responsabilidade com o mercado, com ONGs e com as famílias. Adicionalmente, o afrouxamento da função das políticas, compete com a burocratização do Estado no sentido de reduzir a confiabilidade nos serviços oferecidos aos idoso, bloqueando direitos e deveres. (CRUZ, ROCHA e QUARESMA, 2015)

O Estatuto do Idoso foi uma legislação criada 9 anos depois, em $1^{\circ}$ de outubro de $2003^{6}$ e regulamentou, no plano infraconstitucional, o Art. 230 da Constituição Federal ${ }^{7}$. O Estatuto reforça as diretrizes contidas na Política Nacional do Idoso e unifica leis e políticas até então fragmentadas. Em seu Art. $9^{\circ}$ determina que: 'É obrigação do Estado garantir à pessoa idosa a proteção à vida e à saúde, mediante efetivação de políticas sociais públicas que permitam um envelhecimento saudável e em condições de dignidade”. (BRASIL, 2003)

O título II do Estatuto, reitera todos os direitos fundamentais já declarados na Constituição Federal. Nele, são elencados os direitos à vida, à liberdade, ao respeito e à dignidade, aos alimentos, à saúde, à educação, cultura, esporte e lazer, à profissionalização e ao trabalho, à previdência social, à assistência social, à habitação e ao transporte (BRASIL, 2003).

É pertinente ressaltar aqui que o Estatuto do Idoso o qual entrou em vigor no ano seguinte à sua criação, em 2004, também estabelece o dever do Estado em promover o acesso do idoso à educação. Destaca-se que, com referência à educação, programas que atendam a especificidade dos idosos devem ser incentivados pelo Poder Público, contudo essas iniciativas são incipientes para atender o aumento crescente do número de idosos na sociedade.

Quanto à Saúde, o Estatuto também institui direitos por intermédio do Sistema Único de Saúde (SUS), com garantia de acesso universal e igualitário para prevenção, promoção,

\footnotetext{
${ }^{4}$ Lei n. 8.842, que afirma os direitos sociais da pessoa idosa é um importante instrumento legal que amplia a proteção social para a população idosa.

5 Por meio de ações desenvolvidas pelas Organizações Não Governamentais (ONGs), comunidade, família ou entes municipais.

${ }^{6}$ Lei n. 10.741

7 O Art. 230 garante a proteção ao idoso, como responsabilidade da família, da sociedade e do Estado, que têm o dever de ampará-lo
} 
proteção e recuperação da saúde, incluindo a atenção especial às doenças que afetam o segmento da terceira idade. No entanto questiona-se: essas políticas ou programas de atenção aos idosos estão sendo de fato implementados?

Não é escopo desse artigo aprofundar os argumentos sobre as falhas do sistema de saúde brasileiro. Convém, no entanto, acrescentar que, dentre os direitos sociais, o direito à saúde merece um estudo especial e específico, principalmente para refletirmos sobre as reivindicações de medicamentos, insumos e tratamentos que um número crescente de idosos dirige ao Poder Judiciário com o objetivo de "forçar" o Estado a cumprir o dever que tanto a Constituição quanto o Estatuto lhes impõe.

O Estatuto do Idoso investe igualmente sobre o direito à moradia dando prioridade nos programas habitacionais públicos (reserva de $3 \%$ das unidades). (CRUZ, ROCHA e QUARESMA, 2015)

Quanto à renda dispôs sobre a assistência social estabelecendo nos Art. 33 e seguintes, que a assistência social aos idosos será prestada de acordo com os princípios e diretrizes da Lei Orgânica da Assistência Social que foi regulamentada pela Política Nacional do Idoso. Conforme os ditames do Art. 34, os idosos a partir de 65 anos que não possuem meios de subsistência, nem uma família que o sustente, têm direito ao benefício mensal de um salário mínimo.

Da mesma forma, é assegurado ao idoso, o direito ao trabalho sem discriminação ou fixação de limite máximo de idade, inclusive para concursos, ficando estabelecida a idade como critério de desempate nos concursos públicos. Além disso, o Art. 28 III, assevera que o Poder Público deve criar e estimular programas de "profissionalização especializada para idosos" (inciso I) estimulando novos projetos sociais (inciso II) e empresas privadas para admissão de idosos (inciso III). (CRUZ, ROCHA e QUARESMA, 2015)

Por fim, um outro documento aprovado em 19 de outubro de $2006^{8}$, a Política Nacional da Saúde do Idoso, vem confirmar, em tese, as virtudes normativas da legislação brasileira quando o assunto é direito da pessoa idosa. A Política Nacional da Saúde do Idoso, tem como objetivo "recuperar, manter e promover a autonomia e a independência dos indivíduos idosos, direcionando medidas coletivas e individuais de saúde para esse fim, em consonância com os

${ }^{8}$ Portaria n. 2.528 
princípios e diretrizes do Sistema Único de Saúde”. Na prática, não obstante o reforço teórico, o cumprimento do dispositivo legal ainda é insuficiente (FERREIRA e TEIXEIRA, 2014).

Coerente com tudo o que foi dito acima, os dispositivos legais que reconhecem os direitos das pessoas idosas, foram resultado de lutas dos movimentos e das organizações da sociedade civil que militam na seara dos direitos de todos de modo geral, e dos idosos em particular, igualmente cidadãos, detentores dos direitos humanos fundamentais e dos direitos civis, políticos e sociais assegurados legalmente. Mas apesar dos resultados alcançados, ainda se observa uma grande lacuna entre a lei e a realidade dos idosos no Brasil impondo a permanência das discussões sobre a problemática dos idosos em todos os espaços possíveis. "Somente a aliança contínua da sociedade será capaz de proporcionar uma mudança de paradigma sobre o processo de envelhecimento dos brasileiros mostrando que envelhecer com qualidade de vida é um direito de todos”. (BRUNO e SILVA, 2020).

\section{Considerações Finais}

Todo o desenvolvimento vivenciado pelas sociedades nos últimos tempos tem proporcionado o prolongamento da vida de suas populações idosas e esse é, sem dúvida, um dado positivo, desde que seja acompanhado de boa qualidade de vida. Ter mais tempo de vida não significa ter vida de boa qualidade, pois o acesso às boas condições de vida são prerrogativas do envelhecimento saudável.

No entanto, observa-se no Brasil que, apesar de existirem leis que asseguram direitos para todos, a realidade vivida pelos idosos ainda está longe do exercício pleno da cidadania, uma vez que ainda se mantém, no seio desse grupo populacional, um crescimento imoral e acentuado da desigualdade e da pobreza. Além disso, ser idoso não significa ser incapaz ou frágil e apesar de as políticas públicas serem desenvolvidas em atenção a todos os idosos, especificamente no Brasil e em algumas outras regiões do planeta, é a condição de pobreza que enseja a concretização de direitos.

Pretendeu-se aqui, promover reflexões sobre os direitos dos idosos e, consequentemente, sobre o fenômeno do envelhecimento, pois o aumento da expectativa média de vida das pessoas, vinculado a outros fenômenos como a queda da fecundidade e a taxa de mortalidade, tornou-se uma realidade mundial para a qual nem mesmo os países mais ricos estavam convenientemente preparados. Vários fatores contribuíram para transformar a 
população idosa no componente cada vez mais expressivo dentro da população geral a ponto de se afirmar que o mundo definitivamente está envelhecendo mais rápido.

Esse fenômeno ocorreu graças ao progresso da medicina cuja competência tem permitido o combate às doenças anteriormente consideradas incuráveis, graças à indústria dos alimentos que colocou no ostracismo as previsões de Malthus (1798), filósofo que "previu" a impossibilidade de se produzirem alimentos suficientes para uma população em crescimento acelerado, e graças a melhores condições médico-sanitárias.

Como dito acima, é um fenômeno que ocorreu em escala global, todavia, não foi um processo homogêneo que tenha acontecido em todos os países de maneira análoga. Dados populacionais comprovam que a maioria dos idosos vive nos países do Terceiro Mundo, menos desenvolvidos economicamente. Além disso, ressalta-se a evidência de grandes e notáveis diferenças entre os países desenvolvidos onde essa evolução se deu associada à uma relativa melhoria na qualidade de vida, e os países em desenvolvimento onde o crescimento da população idosa ocorreu pleno de carências. Enfim, o que no passado constituiu uma prerrogativa de poucos, hoje, um número crescente de pessoas desfruta do privilégio de envelhecer, experiência que, no Brasil e em outros países da América Latina consistiu num processo acelerado que não se fez acompanhar de melhora na qualidade de vida das pessoas idosas.

Em um país com um elevado nível de desigualdade como o Brasil e com as enormes dificuldades para alcançar um desenvolvimento econômico satisfatório, reduzindo os índices de pobreza, as legislações destinadas a preservar direitos contribuíram, ainda que formalmente, para minimizar as carências das pessoas idosas, mas não é suficiente. O Brasil precisa se preparar para maiores desafios de uma sociedade ainda mais envelhecida, pois apesar do empenho e do arcabouço legislativo, a eficácia das normas não foi alcançada na sua concretude. Então o que precisa ser feito para assegurar que o idoso tenha direitos exercidos? Esse é o ponto de partida para as reflexões que a sociedade deve se impor em perseguição da construção de um país melhor para todos, inclusive para os mais velhos. 


\section{REFERÊNCIAS}

AGÊNCIA BRASIL. Brasileiros com 65 anos ou mais são 10,53\% da população. Disponível em: https://jornal.usp.br/atualidades/em-2030-brasil-tera-a-quinta-populacao-mais-idosa-domundo/. Acesso em 29.10.2021

ALCÂNTARA, Alexandre de Oliveira. A VELHICE NO CONTEXTO DOS DIREITOS HUMANOS. In: GURGEL, Maria Aparecida e MAIO, Idaya Gama (orgs). Pessoas Idosas no Brasil: abordagem sobre seus direitos. Brasília: Edições Inclusivas, 2007

ALVES, Eliana Calmon. DIREITOS DE QUARTA GERAÇÃO: biodiversidade e biopirataria. Revista do Tribunal Regional do Trabalho da 5a Região, v.4, n.1, p.41-61, dez. 2002.

ALVES, José Eustáquio Diniz. Envelhecimento populacional no Brasil e no mundo. Revista Longeviver, 2019.

BAUMAN, Zygmunt. Modernidade líquida. Tradução Plínio Dentzien - Rio de Janeiro: Zahar, 2003

BOBBIO, Norberto. A era dos direitos. Rio de Janeiro: Editora Campus, 1992

BRASIL. Lei $\mathrm{N}^{\circ} 10.741$ de $1^{\circ}$ de outubro de 2003. Dispõe sobre o Estatuto do Idoso e dá outras providências. Presidência da República, Casa Civil, Subchefia para assuntos jurídicos.

BRUNO, Maíra Bogo; SILVA, Elisa Aparecida Fernandes Rocha. Políticas Públicas como Instrumentos Infraconstitucionais de Garantia da Dignidade Humana da Pessoa Idosa. Revista Humanidades e Inovação v.7, n.2, 2020

CAMARANO, Ana Amélia; PASINATO, Maria Tereza. Os novos idosos brasileiros, muito além dos 60? Introdução. Rio de Janeiro: Instituto de Pesquisa Econômica Aplicada-IPEA, 2004.

COELHO, Marcos Vinícius Furtado. O Direito Constitucional, a Saúde e sua Evolução. In: Consultor Jurídico-CONJUR. Disponível em: https://www.conjur.com.br/2020-mai10/constituicao-direito-constitucional-saude-evolucao. Acesso em: 31.10.2021

COSTA, F. G.; FAVÉRO, M. H. As transformações das representações sociais sobre o envelhecer, o envelhecimento e o idoso: uma pesquisa de intervenção. In. ARAÚJO, L. F. de; CARVALHO, C. M. R. G. de; CARVALHO, V. A. M. de L. As diversidades do envelhecer: uma abordagem multidisciplinar. $1^{a}$ edição. Curitiba: Editora CRV, 2009. Capítulo 5, p. 75-86.

CRUZ, Malutarsis dos Santos; ROCHA, Alinne Meneses; QUARESMA, Amanda Carolina de Lima. Direitos da Pessoa Idosa: desafios para a sua efetivação na atual conjuntura. In: VII Jornada Internacional de Políticas Públicas. São Luiz, 25-28 de agosto de 2015.

DOTTI, René Ariel. A liberdade e o direito à intimidade. Revista de Informação Legislativa, Brasília, n. 66, p. 125-152, abril/junho, 1980. 
FACHIN, Zulmar; FACHIN, Jéssica. DIREITOS HUMANOS EM NORBERTO BOBBIO: A TRAJETÓRIA DE UMA UTOPIA EM BUSCA DE CONCRETIZAÇÃO. Revista Jurídica, vol. 03, $n^{\circ} .60$, Curitiba, 2020. pp. 107 - 125

FELICIANI, Ana Lúcia Alves. Os Velhos e os Novos Direitos dos Idosos. Revista da Faculdade de Direito da UFRGS - no 31, 2013.

FERREIRA, Ana Paula; TEIXEIRA, Solange Maria. Direitos da pessoa idosa: desafios à sua efetivação na sociedade brasileira. Argumentum, vol. 6, n. 1, janeiro-junho, 2014. Universidade Federal do Espírito Santo.

GOTTERT, Débora Teixeira. ARGERICH, Eloisa Nair de Andrade. A Defesa da Dignidade e Bem-Estar do Idoso diante das Inovações da Constituição Federal e Estatuto do Idoso. In: LONDERO, Josirene Cândido e BIRNFELD, Carlos André Hüning (org). Direitos Sociais Fundamentais: contributo interdisciplinar para a redefinição das garantias de efetividade. Rio Grande: Editora da FURG, 2013.

JORNAL DA USP. Em 2030, Brasil terá a quinta população mais idosa do mundo. Publicado e atualizado em 16.10.2019. Disponível em: https://jornal.usp.br/atualidades/em-2030-brasiltera-a-quinta-populacao-mais-idosa-do-mundo/. Acesso em 29.10.2021

MARTINS, Rosa Maria Lopes; SANTOS, Ana Cristina Almeida. Ser Idoso Hoje. Millenium. Journal of Education, Technologies and Health

MORIN, Edgard. A comunicação pelo meio: teoria complexa da comunicação. Revista FAMECOS. Porto Alegre, no 20, abril 2003, p.7-12, quadrimestral.

NUNES, André. O envelhecimento populacional e as despesas do Sistema Único de Saúde. In: CAMARANO, Ana Amélia (org). Os novos idosos brasileiros, além dos 60? Instituto de Pesquisa Econômica e Aplicada-IPEA, 2004

RAMOS, André de Carvalho. Curso de Direitos Humanos. São Paulo: Saraiva, 2019, p. 57.

ROCHA, Carmen Lúcia Antunes. Os Princípios Constitucionais e o Novo Código Civil. Revista da EMERJ, v. 6, n. 22, 2003

SANTILI, Juliana. Os "Novos" direitos socioambientais. Revista DIREITO E JUSTIÇA Reflexões Sociojurídicas - AnoVI - Nº - Novembro 2006

PEREIRA, Rondinelli Santos de Matos; EVANGELISTA, Cláudio Belmino Rabelo; FREITAS, Ana Maria Lima de. VIOLÊNCIA CONTRA A PESSOA IDOSA: DESAFIO CONTEMPORÂNEOPARA A SEGURANÇA PÚBLICA. Ambiente: Gestão e Desenvolvimento. II Seminário do Mestrado Profissional em Segurança Pública, Direitos Humanos e Cidadania.

SARLET, Ingo Wolfgang. Uma Constituição aberta a outros Direitos Fundamentais? In: Revista Consultor Jurídico, 13 de março de 2015. Disponível em: https://www.conjur.com.br/2015-mar-13/direitos-fundamentais-constituicao-aberta-outrosdireitos-fundamentais 
SILVA, Flávia Martins André da. Direitos fundamentais: conteúdo essencial, restrições e eficácia. São Paulo: Malheiros, 2009

WAJNMAN, Simone; OLIVEIRA, Ana Maria; OLIVEIRA, Elzira Lucia. Os idosos no mercado de trabalho: tendências e consequências. In: CAMARANO, Ana Amélia (org). Os novos idosos brasileiros, além dos 60? Instituto de Pesquisa Econômica e Aplicada-IPEA, 2004

WOLKMER, Antonio Carlos. INTRODUÇÃO AOS FUNDAMENTOS DE UMA TEORIA GERAL DOS “NOVOS” DIREITOS. In: Revista Jurídica UNICURITIBA. Vol. 02, n. 31 (2013)

WOLKMER, Antonio Carlos; LEITE, José Rubens Morato. Os "novos" direitos no Brasil: natureza e perspectivas, uma visão básica das novas conflituosidades jurídicas. São Paulo: Saraiva, 2016 